\title{
Research on failure mode and ultimate bearing characteristics of the single pile on different foundation
}

\author{
Bin $\mathrm{Li}^{1,2,3, a}$, Ruiqi Zhang ${ }^{1,2,3}$ \\ 1.Tianjin Port Engineering Institute Ltd. of CCCC First Harbor Engineering Company Ltd., Tian \\ jin, 30222 China \\ 2.Key laboratory of port geotechnical engineering, ministry of communications, PRC \\ Tianjin, 30222 China \\ 3.Key laboratory of port geotechnical engineering of Tianjin, Tianjin, 30222 China \\ aemail: lee_binbin@163.com
}

Key words:Pile foundation; ultimate bearing capacity; Theoretical analysis;Finite element; Abstract:The most common forms of offshore wind turbine foundation are single pile foundation, but the loads and the overturning moment make it different from foundation of offshore oil platforms. The elastic-plastic element of the ABAQUS is to be used to simulate failure modes of pile foundation in soil clay. The results show that the single pile foundation has no plastic strain under ultimate vertical load in soft clay; pile foundation has plastic strain under the ultimate horizontal load; pile foundation has plastic zone in front of the pile under ultimate bending moment load.

\section{Introduction}

Offshore wind power generation technology has become a hot point in recent years, as our country is rich of wind energy resources in broad flat area ${ }^{[1-3]}$. China's offshore wind energy resources are expected to reach 750000000 kilowatts, whichis three times thanonshore wind energy resources, offshore wind power will become the focus of energy development. At present the structure forms of offshore wind power have the gravity type, the pile foundation type, the triangle type, the structure of the jacket and the floating structure. Single pile foundation is used widely in offshore wind farms, but the horizontal load and overturning moment of the offshore wind turbine are much larger than the offshore oil platform, and the vertical load is less, so the bearing characteristics and failure mode of the foundation are different from the offshore oil platform. In particular, the pile diameter $(4 \sim 7 \mathrm{~m})$ of the single pile is far larger than the diameter of offshore oil platform $(1 \sim 2 \mathrm{~m})$. Bearing mechanism of the single pile foundation of offshore wind power generation is the most important point in this paper ${ }^{[4-7]}$.

Research method of bearing characteristics and failure mode of the single pile foundation has many types,elastic-plastic element of the ABAQUS is used to simulate failure modes of pile foundation in soil clay. This method can visualizedreflectmechanical characteristics of offshore wind power generation.

\section{Model parameters}

The finite element software ABAQUS is used to establish the single pile foundation finite element model of different pile diameters. The calculation range of soil foundation is takinglarger to eliminate the effect of boundary effect. In order to better simulate the interaction between piles and soil, this paper chooses Mohr-Coulomb models in the model calculation. The foundation is soft clay foundation, specific parameters as shown in Table 1. In this paper, the failure mode of large diameter piles in the different foundation is studied by theoretical analysis, numerical simulation, and model experiment ${ }^{[8-10]}$.

Six groups pile foundation ofdifferent pile diameters are selected to simulate failure modes of single pile foundation .In the calculation of the vertical ultimate bearing capacity of single pilefoundation, the effect of soil arch effect on the single pile foundation is considered. 
Table 1Soil Parameters

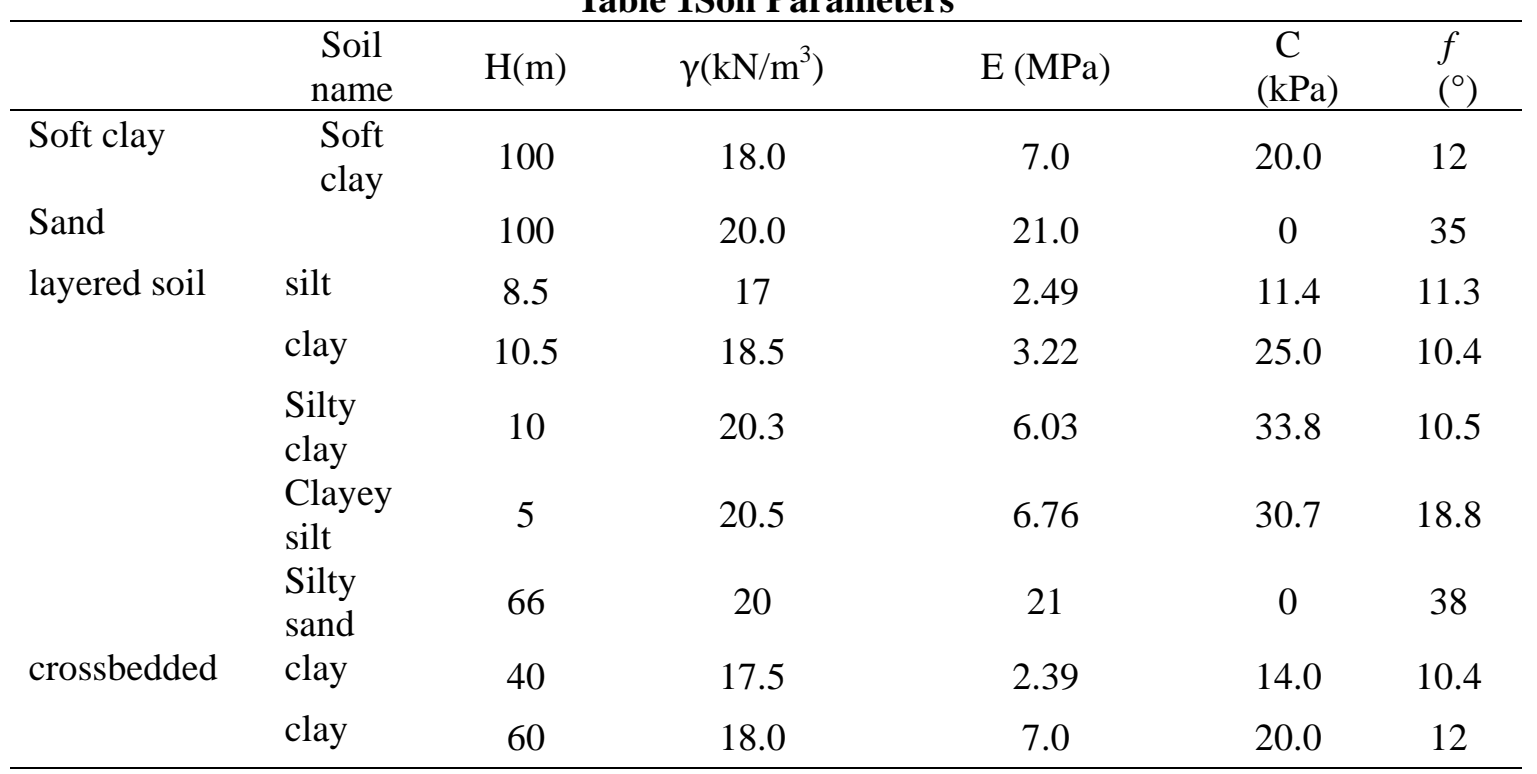

The elastic-plastic model is used for the simulation of pile foundation, and the parameters of the pile material are shown in Table 2.

Table 2 material parameters of pile body material

\begin{tabular}{cccc}
\hline & $\gamma\left(\mathrm{kN} / \mathrm{m}^{3}\right)$ & Poisson's ratio & $\mathrm{E}(\mathrm{MPa})$ \\
\hline Steel pipe pile & 68.5 & 0.3 & $2.1 \times 10^{5}$ \\
Concrete (C60) & 24.5 & 0.2 & $3.0 \times 10^{4}$
\end{tabular}
the soil.

Tangential and normal are respectively friction contact and hard contact between the pile and

Steel type of single pile foundation is Q345, which using the elastic-plastic model, specific material parameters are shown inTable 2, steel plastic material parameters as shown in figure 1.
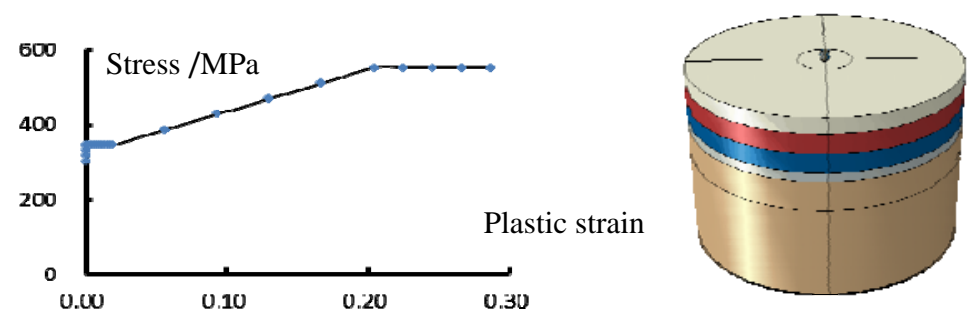

Figure 1 Q345Relationship of stress and strainFigure 2 finite element model diagrams

\section{Foundation failure mode}

The failure mode and bearing characteristics of single pile foundation are analyzed based on the finite element software ABAQUS. The finite element model is shown in Figure 2.

(1) Foundation failure mode under vertical load

When the pile body under the ultimate vertical load in soft clay,the different diameter of pile equivalent plastic strain chartand the distribution of plastic region in soil respectively shown as in Figure3, Figure4.

From Figure 3, it is known that the equivalent plastic strain of piles in different diameters is 0 , which has no plastic strain. Therefore, The ultimate failure mode of single pile foundation under vertical load is the bearing failure in the soil. 


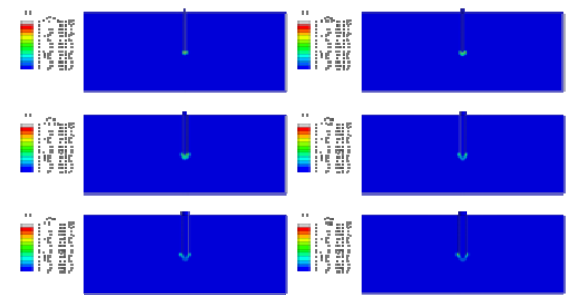

a Soft clay

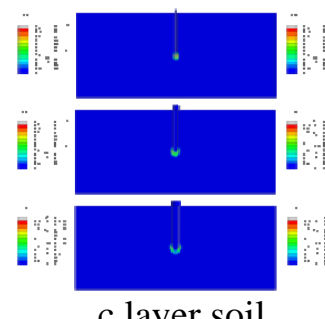

c layer soil

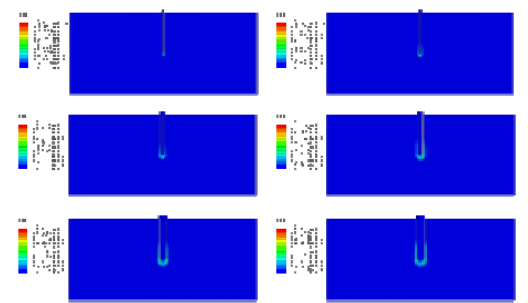

b Sand

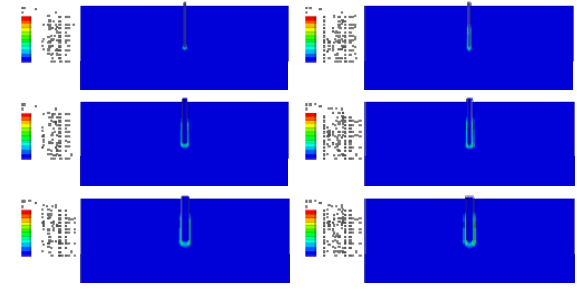

d .crossbeddedfoundation

Fig. 3 distribution of plastic zone in soil

With the change of the pile diameter, the plastic zone distribution in the soil gradually increases,the fracture surface is not extended to the surface of the foundation;the failure of the soil is manifested by local shear failure.With the longer of the pile diameter, the distribution of plastic zone in the soil increases gradually, but the shape is basically the same. The plastic point of the soil is first appeared below soil mass at the side wallin the bottom of the pile foundation, then gradually extension tothe pile bottom soil and both sides of the pile tip soil, the slip surface is formed at the bottom of the pile in the end, the plastic zone in the soil is different from sand soil, not only the pile tip of the plastic zone, but also the pile side appear plastic zone.

(2) Foundation failure mode under horizontal loading

On the foundation, when the pile body under horizontal load, different diameter of pile equivalent plastic strain cloud chart and plastic region distribution in soil and the displacement vector diagram in soil are shown as Figure.
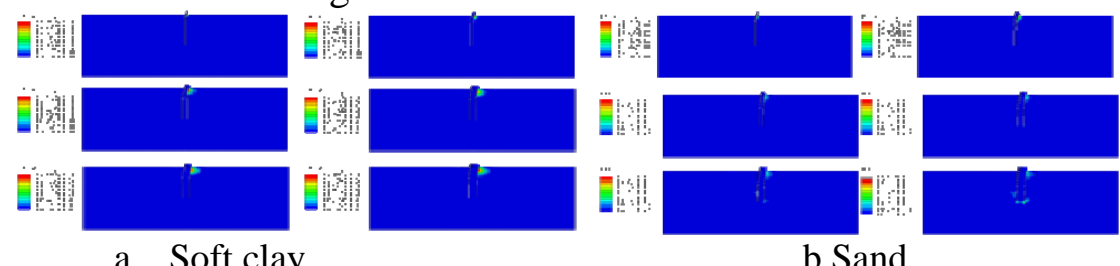

a Soft clay

$$
\text { b Sand }
$$

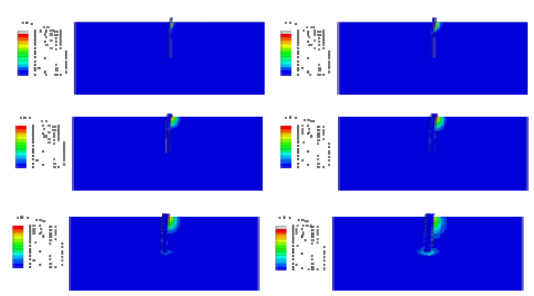

c layer soil

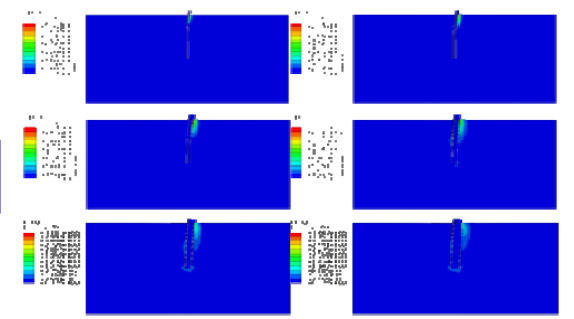

d .crossbeddedfoundation

Fig. 4 distribution of plastic zone in soil

Plastic deformation of piles appearsin different diameter piles under horizontal ultimate load. When the diameter is smaller, the range of the plastic zone is distributed in the upper part of the pile; when the diameter is increased, the plastic zone is distributed in the middle part of the pile.Compared with the sand foundation, the clayed soil foundation has less resistance, and change position of pile body is increased along the load direction when the pile is bearing the horizontal load, and the plastic zone gradually moves down.

On the foundation, when the pile diameter is smaller, the lower part of the pile is embedded in the soil, plastic zone are mainly distributed in the surface of the soil masswhich in the front side of the pile body; when the pile diameter increasing, the shape of plastic zone is always same, the range is gradually increasing,the clayed soil foundation has less resistance,under horizontal load, the large diameter piles( the rigid pile)are turned., and the end of the pile is also distributed in the plastic 
zone.

When the pile diameter is smaller, lower pile is blocking in the soil, the upper part of the pile body moves along the direction of horizontal loads, displacement of pile top is the biggest, and the front side soil is uplifting and the soil of the back side moves to the pile body direction. When the pile diameter increases and the pile body rotation, the upper part of the pile body along the moving direction of horizontal loads, displacement of top pile is the biggest, soil produces spherical rotation failure surface at theend position of pile body, soil uplift in front of pile body, and soil of back side moves to the direction of pile body.

(3) Foundation failure mode under the bending moment.

On the foundation, when the pile body bear bending moment limit load, different diameter of pile equivalent plastic strain cloud chart and plastic region distribution in soil and the displacement vector diagram of pile and the soil as shown in figure.
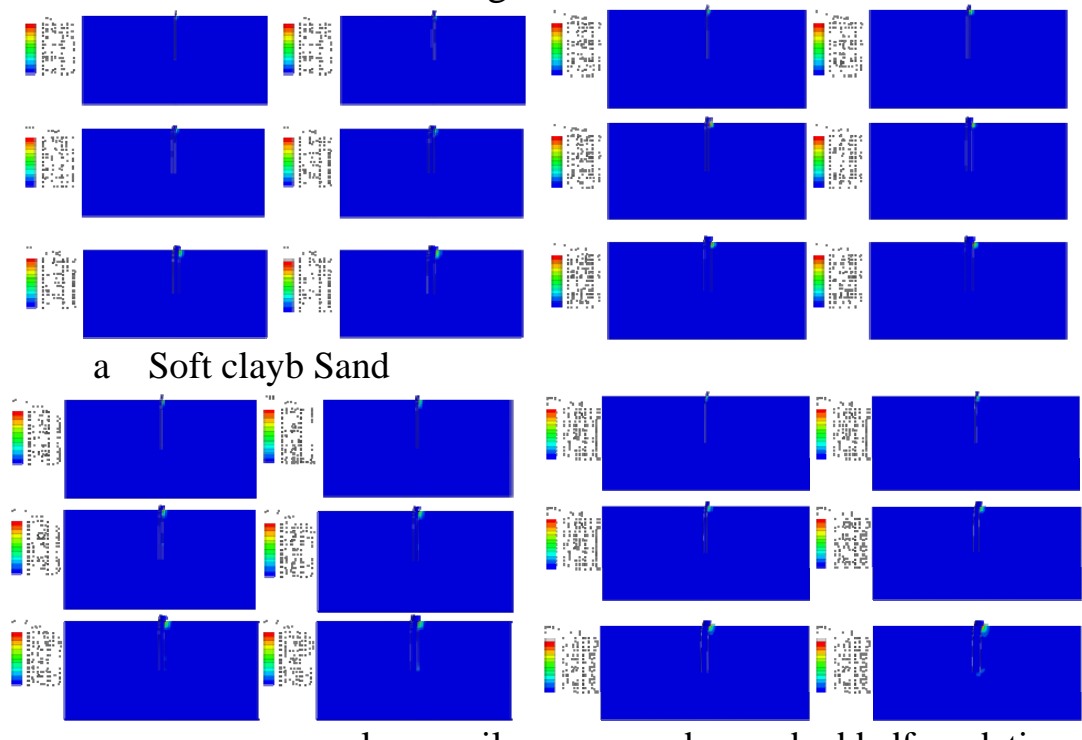

c layer soil

d .crossbeddedfoundation

Fig. 5 distribution of plastic zone in soil

The plastic deformation of piles appears in different diameters of piles under the ultimate bending moment load, the plastic zone is distributed in the area which near the top of the pile,the plastic deformation of the foundation is the same as sand soil foundation, which is different from the plastic zone distribution to shift down of clay under the horizontal load.

It is known that the plastic zone of the soil is mainly distributed in the upper part of the pile body when the pile bodybear bending moment load, Plastic zone is relatively smaller than horizontal load condition. The plastic zone in front ofpile body is increased when the diameter is increased;the distribution of plastic zone is almost unchanged compared with the sand foundation.

The lower pile embedded in clay when pile body bear the moment load, upper pile has rotation, soil in front of pile body is heaved. Whenpile diameter is smaller, a smaller range of soil uplift, the surface soil in back of pile moved towards pile body direction, the situation of the foundationunder bending moment condition is similar to the sand soil.

\section{Conclusion}

In this paper, the bearing characteristics and failure modes of the single pile foundation in soil is analyzed by using the large finite element software ABAQUS.

(1) Single pile on differentfoundation under the vertical ultimate load, no plastic strain, in the elastic working stage, single pile foundation under the vertical load appears failure is the destruction of the soil. The distribution of plastic zone in the soil is closely related to the soil layer of the single pile foundation.

(2) Single pile foundation on different foundation under the horizontal limit load, the pile body has plastic strain; the soil is not at the same time, plastic deformation of the part has a slight change. Single pile foundation bearing layer is clay, soil surface in front of pile side and the pile tip appear 
plastic zone distribution.

(3) The position of the plastic strain of the pile is always the top of the pile, when single pile on different foundation under the bending moment limit load. Soil in the plastic zone is mainly distributed in the soil surface of pile body's front side; plastic zone is smaller when comparing with the horizontal load condition.

\section{Reference}

[1] Global wind report. Global Wind Energy Council. 2010.

[2] European Environment Agency (EEA). Europe's onshore and offshore wind energy potential. 2009.

[3] Lian J J, Sun L Q, Zhang J F, et al. Study on bearing characteristics and technology advantages of the composite bucket foundation of offshore wind turbines. Transactions of Tianjin University. 2011, 17(1): 55-60.

[4] Lian J J, Wang Haijun, Liu Meimei. the foundation of offshore wind turbine[p],2010-10

[5] Lian J J, Ding Hongyan, Zhang Puyang. A combination of guiding and negative pressure technology for thick foundation sinking method[p],2009-10

[6] Lian J J,Wang Haijun. uses the prestressed concrete cylinder type structure of offshore wind turbine foundation[p],2010-10.

[7] Huan Choi. Offshore pile type fan foundation structure design and research of [D]. Dalian University of Technology, 2009

[8] Chen Guangsi, Liu Run, Liu Yuchen, et al. Analysis of the bending characteristics of the wide and shallow cylindrical foundation with offshore wind power [J]. Journal of Tianjin University: Natural Science and engineering technology[J], 2013, 46 (5): 393-400.

[9] Le Cong Huan, Ding Hongyan, Pu Yang Zhang. The deck concrete bucket foundation of offshore wind turbine bearing model. Engineering mechanics[J] 2013, 30 (4): 429-434. 